\title{
A new technique to reduce residual air emboli in open left cardiac surgery
}

\author{
Bansi Lal Koul, MD, PhD, ${ }^{a}$ Faleh Al-Rashidi, MD, ${ }^{a}$ Anders Roijer, MD, PhD, ${ }^{\mathrm{b}}$ and Carl Meurling, MD, PhD, ${ }^{\mathrm{b}}$ \\ Lund, Sweden
}

Residual air emboli, as seen on intraoperative transesophageal echocardiographic (TEE) analysis after termination of cardiopulmonary bypass (CPB) for true open left cardiac surgery, might lead to ventricular dysfunction, life-threatening arrhythmias, and transient or permanent neurologic deficits. ${ }^{1,2}$ These residual air emboli can show on TEE analysis for as long as 28 minutes after the termination of $\mathrm{CPB} .{ }^{3}$ We report here an original technique of cardiac deairing that is aimed at reducing residual air emboli by (1) minimizing air from entering into the pulmonary veins and (2) flushing out residual air from the lungs, even at low right cardiac output.

\section{CLINICAL SUMMARY}

After CPB, both pleural cavities are exposed through a small opening, one on either side in the mediastinal pleura. The patient is disconnected from the ventilator, allowing both lungs to collapse. After completion of the surgical procedure and release of the aortic crossclamp, the heart is defibrillated, rewarming is continued, and deairing is begun. The left ventricle is vented continuously to prevent cardiac ejection. Inotropic drugs, systemic arterial vasoconstrictors, or both are used as and when necessary to generate an adequate systemic blood pressure and good cardiac contraction. The left ventricular preload is now successively increased by reducing the venous return to the heart-lung machine, and deairing is continued under TEE monitoring. When air emboli are no longer observed in the left side of the heart, the patient is reconnected to the ventilator, and lungs are ventilated with half of the estimated minute volume using $100 \%$ oxygen and $5 \mathrm{~cm} \mathrm{H}_{2} \mathrm{O}$ positive end-expiratory pressure. The left ventricular preload is increased successively, and the lungs are fully ventilated. When the deairing is deemed complete, the left ventricular vent is reduced, and the left heart is allowed to eject. Subsequently, the left ventricular vent is removed, and the patient is weaned from CPB.

From Cardiothoracic Surgery ${ }^{\mathrm{a}}$ and Cardiology, ${ }^{\mathrm{b}}$ Heart and Lung Division, University Hospital Lund, Lund, Sweden

Received for publication Sept 16, 2008; accepted for publication Oct 3, 2008; available ahead of print March 9, 2009.

Address for reprints: Bansi Lal Koul, MD, PhD, Cardiothoracic Surgery, University Hospital Lund, 22185 Lund, Sweden (E-mail: bansi.koul@skane.se).

J Thorac Cardiovasc Surg 2009;138:1438-9

0022-5223/\$36.00

Copyright (c) 2009 by The American Association for Thoracic Surgery doi: $10.1016 /$ j.jtcvs.2008.10.004
Ten patients (study group) undergoing true open left cardiac surgery during CPB for various left heart lesions were investigated prospectively for the residual air emboli by using the deairing protocol discussed above. Another 10 patients treated similarly but in whom the pleural cavities were not opened served as the control group. Patients with a history of chronic obstructive pulmonary disease, previous chest injury or operation, or both were excluded from the study. Weaning from CPB was uneventful in all patients. There was no statistically significant difference in the median CPB times, aortic occlusion times, and postoperative ventilator times between the groups. No patient had hemothorax or pneumothorax perioperatively.

The median deairing time was 10 minutes in the study group and 17 minutes in the control group $(P<.001$, Wilcoxon test). Directly after weaning from $\mathrm{CPB}$, the left atrium, the left ventricle, and the ascending aorta were monitored continuously for 10 minutes on TEE analysis (3chamber view) for residual air emboli (Table 1). In the first 3-minute interval, the residual air emboli varied from grade 0 to I in $9(90 \%)$ patients in the study group compared with 1 $(10 \%)$ patient in the control group. At the end of the 10-minute observation period, $9(90 \%)$ patients in the study group had no residual emboli compared with only $2(20 \%)$ patients in the control group (Table 1).

\section{DISCUSSION}

The cardiac deairing technique reported here reduced the cardiac deairing time significantly (10 vs 17 minutes), and the freedom from residual air emboli (grade 0-I) was obtained in $90 \%$ patients already during the first 3 minutes after weaning from CPB compared with $10 \%$ of patients in the control group (Table 1). These results are comparable, if not better, with those achieved with carbon dioxide insufflation in the mediastinum. ${ }^{4}$

The deairing technique described here reduces residual air emboli, probably as a result of 1) induced collapse of the lungs that in turn decreases the quantity of air entering the pulmonary veins at the exposure of the beating or empty left heart to the ambient air and 2) the pulmonary veins, especially those draining the anterior segments, kink and/ or collapse because of the induced pulmonary collapse, thus preventing entrapment of the ambient air. In the early deairing phase, with the lungs still in a collapsed state, even low right heart output is sufficient to fill the lungs 
TABLE 1. Residual air emboli 10 minutes after termination of CPB $(n=20)$

\begin{tabular}{|c|c|c|c|c|c|c|c|c|}
\hline \multirow{3}{*}{$\begin{array}{c}\text { Minutes after } \\
\text { termination of CPB } \\
\end{array}$} & \multicolumn{4}{|c|}{ Study group $(n=10)$} & \multicolumn{4}{|c|}{ Control group $(n=10)$} \\
\hline & \multicolumn{4}{|c|}{$\mathbf{N}$} & \multicolumn{4}{|c|}{$\mathbf{N}$} \\
\hline & Grade* 0 & Grade I & Grade II & Grade III & Grade 0 & Grade I & Grade II & Grade III \\
\hline $0-3$ & 1 & 8 & 1 & 0 & 1 & 0 & 1 & 8 \\
\hline $4-6$ & 9 & 0 & 1 & 0 & 0 & 4 & 5 & 1 \\
\hline $7-10$ & 9 & 1 & 0 & 0 & 2 & 3 & 4 & 1 \\
\hline
\end{tabular}

$C P B$, Cardiopulmonary bypass. *Transesophageal echocardiographic 3-chamber view: grade 0, no residual air emboli; grade I, air emboli observed in 1 of the 3 chambers (left atrium, left ventricle, and aortic root) during 1 cardiac cycle; grade II, air emboli observed simultaneously in 2 of the 3 chambers during 1 cardiac cycle; grade III, air emboli observed simultaneously in all 3 chambers during 1 cardiac cycle.

completely, with blood flushing all entrapped air within them. Successive increase in the right ventricular preload coupled with a delayed and staged increase in the minute volume ventilation maintains the pulmonary veins free from air until the patient is completely weaned from CPB.

In conclusion, the deairing technique reported here is simple, reproducible, controlled, safe, and effective. Moreover, it is cost-effective because the deairing time is short, and no extra expenses are involved.

\section{References}

1. Komukai K, Hirooka K, Taneike M, Yasuoka Y, Yamamoto H, Hashimoto K, et al. ST elevation during open heart surgery-floating air bubble in saphenous vein graft. Images in cardiovascular medicine. Circulation. 2005;111:e374.

2. Abu-Omar Y, Cifelli A, Matthews PM, Taggart DP. The role of microembolisation in cerebral injury as defined by functional magnetic resonance imaging. Eur $J$ Cardiothorac Surg. 2004;26:586-91.

3. Tingleff J, Joyce FS, Pettersson G. Intraoperative echocardiographic study of air embolism during cardiac operations. Ann Thorac Surg. 1995;60:673-7.

4. Svenarud P, Persson M, van der Linden J. Effect of CO2 insufflation on the numbe and behavior of air microemboli in open-heart surgery: a randomized clinical trial. Circulation. 2004;109:1127-32.

\title{
Thoracic esophagostomy: A novel surgical approach for preservation of esophageal length for use in subsequent reconstruction
}

\author{
Craig R. Moores, BA, and Darroch Moores, MD, Albany, NY
}

We report two cases of end thoracic esophagostomy. This novel approach can be utilized to preserve esophageal length for reanastomosis in secondary reconstruction.

\section{CLINICAL SUMMARY \\ Patient 1}

The first patient was a newborn male patient with necrosis of the stomach, colon, and small bowel due to maternal abuse of crack cocaine. At 24 hours of age, the infant underwent total gastrectomy, right hemicolectomy, and subtotal small bowel resection. Due to intraoperative instability, reconstruction was delayed. An end esophageal thoracic

\footnotetext{
From the Albany Medical College, Albany, NY

Received for publication Sept 4, 2008; accepted for publication Sept 27, 2008; available ahead of print May 11, 2009.

Address for reprints: Darroch Moores, MD, Albany Medical College, Department of Thoracic Surgery, 43 New Scotland Ave, Albany, NY 12208 (E-mail: dmoores1@ nycap.rr.com).

J Thorac Cardiovasc Surg 2009;138:1439-41

$0022-5223 / \$ 36.00$

Copyright (c) 2009 by The American Association for Thoracic Surgery

doi:10.1016/j.jtcvs.2008.09.054
}

esophagostomy was performed posteriorly through a resected portion of the 10th rib, just lateral to the paraspinal muscles (Figure 1,A). The infant was then allowed to grow and stabilize for 3 months with a feeding jejunostomy. At 3 months, the esophagostomy was taken down and the infant was reconstructed. The midtransverse colon was isolated as used with an end-to-side esophagocolostomy and a Roux-en-Y jejunocolostomy (Figure 1, B). Subsequently, he has done well and thrived.

\section{Patient 2}

The second patient was a 78-year-old woman with severe coronary artery disease, diabetes, and chronic renal failure, who underwent laparoscopic repair of a massive hiatal hernia at an outside institution. A polytetrafluoroethylene patch was used in the hiatus. The patient developed a postoperative gastric fistula, a subphrenic abscess, and sepsis. The subphrenic abscess was drained percutaneously; she was stabilized and transferred to our hospital.

Subsequently, the patient developed an undilatable stricture at the gastroesophageal junction. At 4 weeks following 